\author{
${ }^{1}$ Agus Suharto, ${ }^{2}$ Siti Bahiroh, ${ }^{3}$ Cahyo \\ Setiadi Ramadhan \\ ${ }^{1}$ Fakultas Kedokteran dan IImu Kesehatan, \\ 2,3Fakultas A gama Islam \\ Universitas M uhammadiyah Yogyakarta \\ Jalan Brawijaya, Tamantirto, Kasihan, \\ Bantul, Yogyakarta 55183 \\ Email: a_suharto@yahoo.com
}

\section{Layanan Kesehatan Swadaya Masyarakat untuk Lansia}

The N on-G overnmental H ealth Service For E Iderly People

https:/ / doi.org/ 10.18196/ bdr.7268

\begin{abstract}
The high number of elderly people in Dagen Hamlets, Pendowoharjo, Bantul requires special highlight, especially regarding the health care. This urgency is due to the fact that elderly people generally have accessibility limitations in addition to the remote location of health facilities. Therefore, health service which is practical and easy-to-reach/ access by the elderly people needs to be managed to take place. The society empowerment effort, especially towards elderly people, was conducted step-by-step, involving socializations, trainings, practices, and local health service facility establishment. The success indicator achieved in this empowerment activities is shown by the improvement of people's awareness, especially the elderly ones, towards the significance of health, health service post visitation intensity, and the development of the non-governmental health service facility. Keywords: Elderly people, health service, non-government, health service post
\end{abstract}

\title{
PENDAHULUAN
}

Pedukuhan Dagen merupakan salah satu pedukuhan atau dusun dari Kelurahan atau Desa Pendowoharjo. Berdasarkan wawancara awal kepada perangkat dukuh diketahui penduduk Pedukuhan Dagen berjumlah 1.182 jiwa, terdiri 533 laki-laki dan 629 perempuan. Pedukuhan ini terdiri atas 3 Rukun Tetangga (RT). H asil wawancara kepada beberapa anggota masyarakat dan pengamatan awal menunjukkan masyarakat pedukuhan memiliki berbagai kegiatan kemasyarakatan baik kegiatan sosial, agama, budaya, maupun kesehatan.

Kegiatan keagamaan terdiri atas pengajian muslimah, tahlilan oleh muslim laki-laki, dan sembahyangan oleh U mat Katolik. Hasil pengamatan awal menunjukkan bahwa dalam kegiatan keagamaan tersebut masyarakat tidak hanya melaksanakan ritual keagamaan atau menuntut ilmu keagamaan, tetapi juga terjadi interaksi sosial antarmasyarakat yang mengikutinya. $\mathrm{H}$ al tersebut juga didukung pernyataan beberapa anggota pengajian muslimah bahwa kegiatan tersebut juga merupakan ajang "silaturahim". 


\section{5}

Adapun kegiatan sosial yang dilaksanakan terdiri atas perkumpulan Pembinaan Kesejahteraan Keluarga (PKK) tingkat RT dan tingkat pedukuhan, seperti kegiatan keagamaan dalam kegiatan sosial tersebut terjadi interaksi masyarakat. Selain itu, anggota PKK yang beranggotakan perempuan juga melakukan arisan dan membahas berbagai kegiatan yang dianjurkan oleh pemerintah desa. Pada kesempatan pertemuan PKK tersebut, Ibu Dukuh Dagen menyampaikan informasi terbaru dari kelurahan seperti lomba kesehatan lingkungan hidup, senam untuk warga lanjut usia (lansia), lomba bayi sehat, dan lain-lain.

Kegiatan sosial jugaterkadang dikaitkan dengan kesehatan, sebagai contoh, masyarakat menggumpulkan dana dari kelompok D asawisma untuk mengadakan Kesling (Kesehatan Keliling). Selain itu, anggota masyarakat juga melakukan kegiatan Pos Pelayanan Terpadu (Posyan du). Kedua kegiatan tersebut dilaksanakan bekerjasama dengan Pusat Kesehatan M asyarakat (PKM / Puskesmas) setempat. Kegiatan tersebut dilakukan karena baik tokoh sosial desa maupun petugas Puskesmas merasa kesadaran warga mengenai kesehatan masih perlu ditingkatkan. Berdasarkan hasil wawancara awal, masyarakat menganggap kondisi sehat hanya apabila tidak merasakan adanya penyakit di tubuh. Masyarakat menganggap memeriksakan diri di saat sehat adalah hal yang aneh. Walaupun kesehatan merupakah hal yang penting dalam kehidupan masih banyak yang abai. Nila Djuwita F. M oeloek mengakui bahwa baru dua puluh persen (20\%) penduduk Indonesia yang sadar kesehatan (Pardiana, 2017).

Baik dari hasil pengamatan maupun wawancara awal diketahui kondisi ini juga terjadi pada masyarkat lanjut usia (lansia) D ukuh D agen. Kurangnya kesadaran lansia tersebut disebabkan berbagai faktor. M enurut hasil telaah awal di lokasi pengabdian, diketahui bahwa kebanyakan lansia di Pedukuhan Dagen tidak berpendidikan tinggi. Kurangnya kesadaran mengenai kesehatan menjadi faktor utama lansia tidak memeriksakan kesehatan (Yamaguchi, et al., 2018). Hal yang sama juga terjadi di daerah D agen.

$\mathrm{H}$ al lain yang dapat memicu kondisi non-participation tersebut, yaitu masyarakat lansia merasa kesulitan menjangkau layanan kesehatan yang dibutuhkan dan sesuai dengan kondisi mereka (affordable). Kelompok lansia tentu mengalami penurunan kondisi, termasuk penurunan mobilitas (Lazarus dan Lazarus, 2006). Kondisi ini memunculkan hambatan dalam mobilitas sosial atau gerak keseharian Iansia (Stuart-H amilton, 2006). Layanan kesehatan yang terbuka bagi masyarakat yaitu puskesmas hanya berjumlah dua dengan 8 dokter umum, 3 dokter gigi, 30 perawat dan bidan, 1 farmasis, 4 ahli gizi, dan 10 tenaga kesehatan lainnya (BPS, 2018). Jumlah tersebut tentu kurangideal dibandingkan 
dengan kawasan yang harus dilayani yaitu satu Kecamatan Sewon yang menurut data BPS seluas $2.716 \mathrm{H}$ a. dan berpenduduk 115.683 jiwa. Masyarakat juga merasakan jarak tempuh dari pedukuhan mereka ke puskesmas cukup jauh yaitu 3,2 $\mathrm{Km}$ yang terdekat dan memakan biaya dan tenaga.

Selain layanan berupa Puskesmas, di Keluruhan Pendowoharjo terdapat 3 klinik. Tidak semua warga dapat memeriksakan dirinya di klinik tersebut karena warga lansia belum tentu dapat menggunakan program Badan Penyelenggara Jaminan Sosial (BPJS) apabila berobat pada klinik tersebut. Padahal penggunakan jaminan sosial untuk berobat jalan di Kabupaten Bantul cukup besar yaitu mencapai 38,8\% (BPS, 2017). Dapat dikatakan bahwa kondisi ini juga mempersulit kebanyakan lansia di Pedukuhan Dagen dalam memeriksakan kesehatan mereka. Kebanyakan lansia berprofesi sebagai petani, buruh, atau pedagang di pasar dan berada pada tingkat ekonomi menengah ke bawah. $\mathrm{H}$ al ini menjadikan sumber daya keuangan untuk kesehatan juga berkurang.

Berbagai kondisi tersebut memunculkan kondisi lansia cenderung tidak memeriksakan kesehatan mereka saat tidak merasakan sakit (non-participation in a physical checkup examination). Padahal, sudah beberapa kali terjadi di desa lansia yang terlihat sehat tetapi tibatiba sakit (akut) kemudian meninggal dunia. Ternyata hasil diagnosismenunjukkan sakit lansia tersebut kronis (sudah berlangsung lama) tetapi tidak dirasakan atau tidak diperiksakan oleh yang bersangkutan. Saat terjadi keadaan tersebut, warga lansia cenderung membicarakannya dan menyatakan khawatir mengalami kondisi demikian. A kan tetapi, setelah kejadian tersebut berlalu beberapa waktu, mereka tidak membicarakannya lagi dan kecenderungan memeriksakan diri di saat merasa sakit saja masih terjadi.

Tentu hal ini menjadi perhatian pemerintah dan masyarakat. Terlebih kesulitan menjangkau layanan kesehatan juga merupakan faktor yang dapat memperburuk kesehatan lansia (M ier, O ry, Towne Jr., dan Smith, 2017). Di lain pihak, topik kesehatan menjadi penting bagi lansia karena mereka lebih beresiko untuk mengalami beberapa gangguan kesehatan dan saat kesehatannya terganggu dapat berkembang menjadi ketidaksejahtreaan psikologis (Lazarus dan Lazarus, 2006). Dipandang dari sisi jumlah, persentase lansia untuk wilayah Bantul saat ini cukup signifikan yaitu $8,47 \%$ dari keseluruhan penduduk (BPS, 2017). National Institutes of $\mathrm{H}$ ealth, dan World $\mathrm{H}$ ealth O rganization (2011) juga menyarankan perhatian lebih mengenai kesehatan lansia mengingat persentasenya yang semakin meningkat secara global. U ntuk itu, perlu dilakukan upaya bersama masyarakat Pedukuhan Dagen untuk men gatasi kendala yang 
dihadapi.

Puskesmas dan masyarakat sudah berusaha menyelenggarakan layanan kesehatan tetapi masih adahal-hal yang dapat ditingkatkan. Layanan yang diberikan dari kegiatan kesehatan yang diusahakan masyarakat hanyalah penyuluhan. Baik pihak puskesmasmaupun tokoh sosial pedukuhan menyadari bahwa masyarakat pedukuhan masih tidak bisa secara bebas mengakses layanan kesehatan yang memadai.

Peluang yang ada di lingkungan yaitu terdapat Klinik Rahma M edika yang bersedia bekerjasama dengan masyarakat. M asyarakat Pedukuhan D agen memiliki potensi untuk mendanai sebuah layanan kesehatan sebagaimana yang telah disebutkan. Berdasarkan pengumpulan data awal, lansia juga memiliki kemampuan untuk menghimpun dana yang tidak sedikit. M ereka dapat mengumpulkan dana dari infaq pengajian ibu-ibu ataupun tahlilan bapak-bapak. $\mathrm{H}$ al ini memungkinkan terbangunnya sinergi masyarakat Pedukuhan Dagen untuk mempermudah lansia Pedukuhan D agen mendapatkan layanan kesehatan baik kuratif ataupun preventif. Pengertian preventif yaitu pemeriksaan lebih awal dapat menghasilkan diagnosis lebih awal sehingga pengobatan/ kuratif juga dapat lebih dahulu dilakukan.

Berdasarkan hal tersebut, terdapat beberapa solusi yang ditawarkan.

1. Pendampingan dan pelatihan pengembangan layanan kesehatan yang rutin dan dapat diakeses serta sesuai dengan kebutuhan masyarakat lansia Pedukuhan D agen. Layanan sesuai kebutuhan lansia yaitu cek gula darah, kolesterol asam urat, jantung, dan lainlain. A dapun yang dimaksud den gan dapat diakses yaitu layanan kesehatan diadakan di masyarakat. Menurut Shrivastava, Shrivastava, dan Ramasamy (2013) layanan kesehatan bagi lansia perlu yang berbasis komunitas atau terjangkau secara lokasi. Layanan yang terjangkau secara lokasi tersebut memanfaatkan potensi yang sudah dimiliki oleh masyarakat Desa Dagen,

2. Pendampingan dan pelatihan untuk mengumpulkan dana swadaya khusus untuk keperluan kesehatan warga lansia. Solusi kedua ini merupakan jawaban bagi solusi pertama yang membutuhkan adanya sumber daya berupa dana untuk keberlangsungan layanan kesehatan yang dimaksudkan. Dana swadaya ini memanfaatkan potensi di masyarakat sebagai M itra Pertama yaitu adanya pertemuan dan pengumpulan dana sosial seperti iuran D asawisma dan infaq pengajian atau tahlilan rutin.

U paya masyarakat lansia untuk menyediakan dana secara mandiri bagi terwujudnya layanan kesehatan bagi mereka merupakan hal yang disarankan dalam layanan kesehatan Iansia. A rai, et al (2012) menyarankan agar lansia dapat berpartisi pasi aktif 
dan berkontribusi termasuk dalam layanan kesehatan.

3. Pelatihan dan pendampingan kesadaran warga lansia dalam memelihara kesehatan secara preventif. Pada kegiatan sosial maupun sosial keagamaan, masyarakat lansia Dagen juga belajar mengenai kesehatan lansia. Promosi kesehatan dalam kegiatan sosial lansia sesuai dengan saran Golinowska, Groot, Baji, dan Pavlova (2016) agar promosi kesehatan juga dapat menstimulasi sosialisasi lansia karena kesepian merupakan salah satu masalah lansia.

4. Penambahan alat kesehatan yang diperlukan untuk layanan swadaya. $\mathrm{H}$ al ini diperlukan untuk meningkatkan kualitas layanan kesehatan swadaya bagi lansia. Dengan pemberian alat ini, dana swadaya lansia dapat dialihkan untuk keperluan lainnya, seperti mengembangkan layanan atau membeli peralatan lain yang lebih murah. $\mathrm{H}$ al ini juga termasuk peningkatan kapasitas masyarakat dalam menjalankan kesehatan swadaya.

\section{METODE PELAKSANAAN}

M enghadapi berbagai permasalahn tersebut, metode pendekatan penyelesaian masalah ditawarkan dalam Program Kemitraan Masyarakat. Masalah fasilitas diatasi dengan mengadakan layanan kesehatan di masyarakat secara secara berkala dengan mengandalkan sumber daya swadaya masyarakat. Pihak UMY memfasilitasi, mendampingi, dan memberikan dukungan dalam proses sinergi masyarakat. Setelah itu, dilakukan pengumpulan data lanjutan kepada masyarakat untuk memantapkan hasil yang telah diperoleh dari pengumpulan data awal. Setelah itu, dibahas langkah-langkah yang dapat dilakukan dalam upaya mewujudkan layanan kesehatan bagi masyarakat. Pertemuan difasilitasi hingga dapat dicapai kesepakatan masyarakat mengenai system layan an swadaya yang dapat berkelanjutan (sustainable). Tim U MY tetap mendampingi hingga sistem layanan swadaya tersebut dapat terlaksana dan dievaluasi.

U ntuk menguatkan dorongan masyarakat dalam menyel en ggarakan layanan kesehatan swadaya sehingga layanan dapat sustain maka dilakukan juga edukasi tentang sistem pelaksanaan layanan swadaya kesehatan kepada masyarakat. Edukasi memanfaatkan pertemuan-pertemuan sosial kemasyarakatan selain untuk memperkuat pemahaman dalam rangka pelaksanaan layanan swadaya, edukasi juga dimaksudkan untuk menumbuhkan kesadaran kehidupan yang sehat bagi lansia. Edukasi ini juga dilakukan dalam pelayanan-pelayanan kesehatan agar lansia tidak men ganggur saat men unggu giliran diperiksa. 


\section{9}

Melalui penjelasan sebelumnya dapat disusun kerangka berpikir Program Kemitraan M asyarakat sebagaimana berikut.

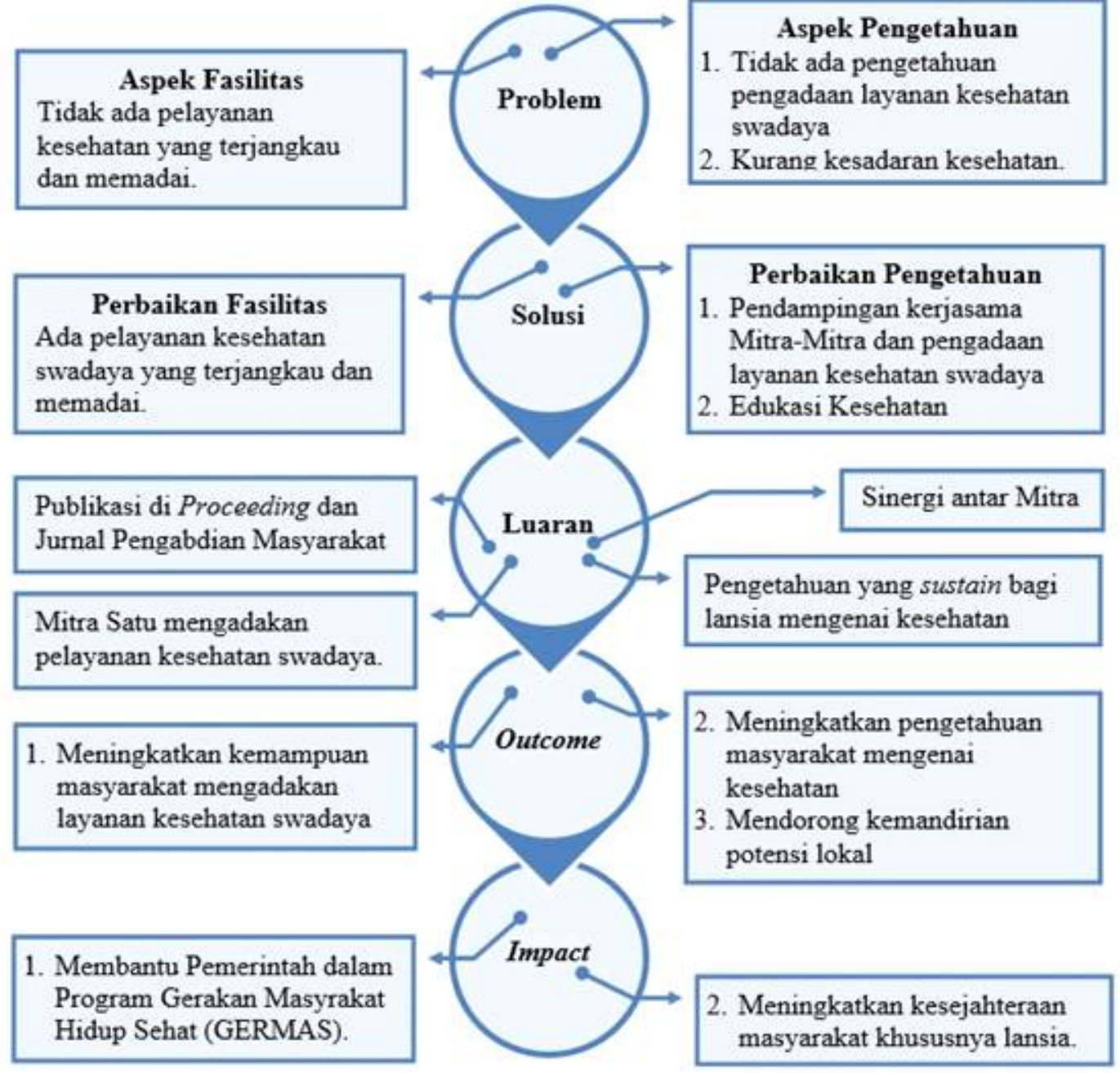

Gambar 1. Kerangka Pikir Program Kemitraan Masyarakat

\section{HASIL DAN PEMBAHASAN}

Terjadi perkembangan di lapangan dalam pelaksanaan program yang memunculkan perubahan-perubahan. Kegiatan dilangsungkan mengacu kepada rencana awal namun berbelit-belit (intertwined) karena kesamaan objek kegiatan atau perhitungan ketersediaan waktu.

1. Fasilitasi Pertemuan Masyarakat yang dilakukan pada 23 Februari 2019 di Masjid Miftahul Jannah pukul 20.00-21.00 WIB. Diskusi pengabdi, dihasilkan bahwa masyarakat dan pelaksana program akan saling bekerja sama.

2. Pelaksanaan Layanan Kesehatan Berkala yang dilakukan pada 24 Februari 2019 pukul 
09.00-12.00 di halaman rumah tokoh masyarakat pedukuhan di dekat M asjid M iftahul Jannah. Hasil pemeriksaan menunjukkan beberapa lansia ternyata memerlukan pemeriksaan lebih lanjut dan beberapa memerlukan pengobatan. Kondisi ini menunjukkan manfaat Layanan Kesehatan Berkala di lingkungan masyarakat sehingga memun gkinkan deteksi dan penanganan dini. Selain pemerikasaan, juga dilaksanakan penyuluhan kesehatan oleh dr. A gus Suharto, Sp.PA.

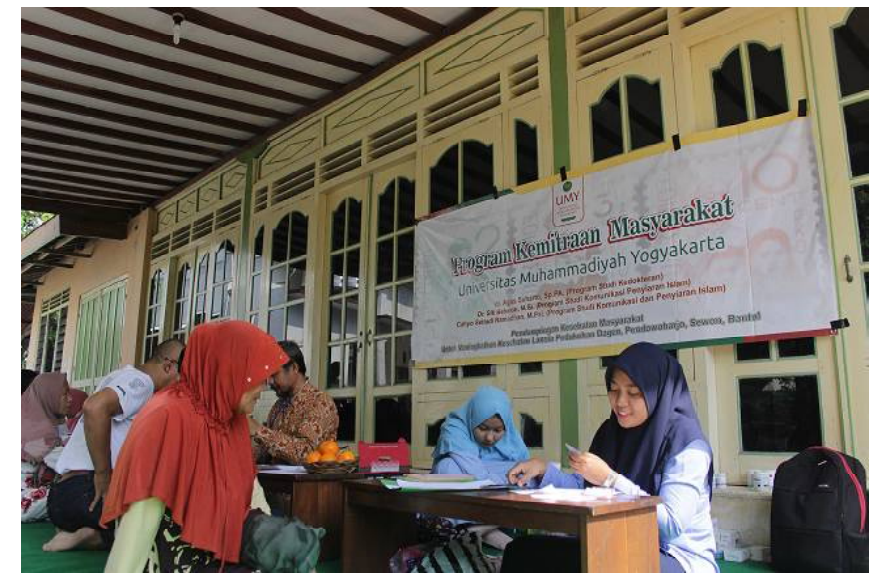

Gambar 2. Pemeriksaan Kesehatan

3. Peningkatan Fasilitas Layanan Kesehatan yan gdilakukan dengan pengadaan peralatan kesehatan pratama yang bisa digunakan masyarakat dengan kemampuan cukup. A dapun untuk pemeriksaan lanjutan dapat dilakukan dengan sistem rujukan kepada klinik mitra kemudian kepada dokter keluarga bersan gkutan. Sistem ini menjadikan pemeriksaan kesehatan dapat dilakukan semakin sering. Peralatan yang diserahkan kepada masyarakat untuk deteksi dini yaitu peralatan tensi darah, termometer, timbangan, cek gula darah, cek kolesterol, dan cek asam urat. Selain peralatan, diserahkan juga bahan habis pakai berupa kapas, alkohol, dan strip pen guji.

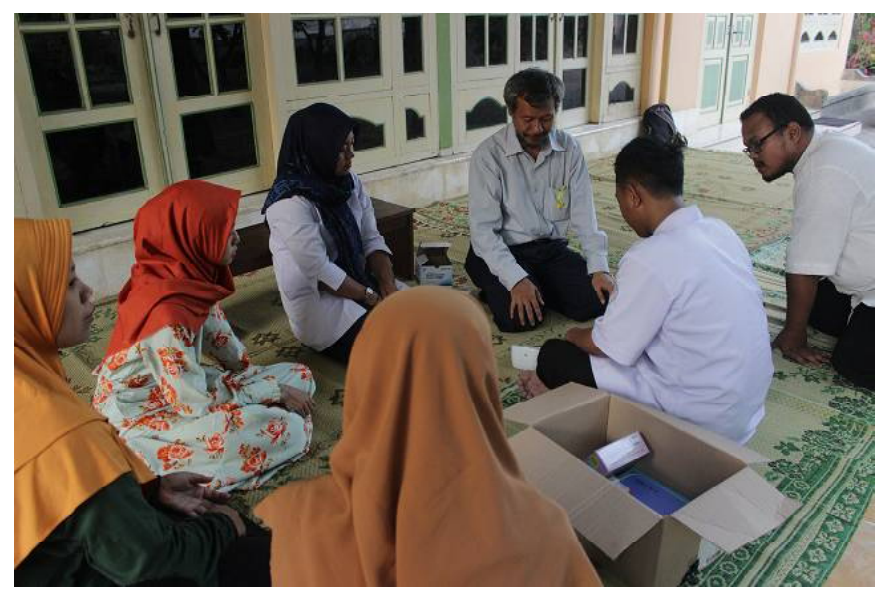

Gambar 3. Pelatihan Penggunaan Alat 


\section{1}

Kader masyarakat yang akan menggunakan alat memiliki latar belakang pendidikan ilmu kesehatan sehingga dapat menggunakan alat yang telah diserahkan. A gar lebih memastikan kader tersebut memahami penggunakan alat dengan baik, dilakukan pula pelatihan penggunaan alat.

4. Edukasi Layanan Kesehatan Swadaya Berkala yaitu menjelaskan kepada masyarakat mengenai mengenai urgensi pemeriksaan kesehatan berkala. Kesediaan masyarakat untuk menjadi mitra dan mengadakan Pelayanan Kesehatan Berkala menunjukkan penerimaan masyarakat edukasi yang dilakukan.

5. Edukasi Kesehatan dan Psikoedukasi Kesehatan M ental kepada masyarakat khususnya Iansia juga dilakukan. Kegiatan ini dilakukan dalam bentuk edukasi kesehatan mengenai pantangan-pantangan makan atau gaya hidup berdasarkan hasil pemeriksaan. Kegiatan ini dilakukan pada saat Pemeriksaan Kesehatan Berkala pada 24 Februari 2019 pukul 09.00-12.00 di halaman rumah tokoh masyarakat pedukuhan di dekat M asjid M iftahul Jannah. Psikoedukasi Kesehatan M ental dilakukan dalam bentuk ceramah oleh pada $17 \mathrm{M}$ ei 2019 pukul 16.00-17.30 di halaman rumah tokoh masyarakat pedukuhan di dekat M asjid M iftahul Jannah.

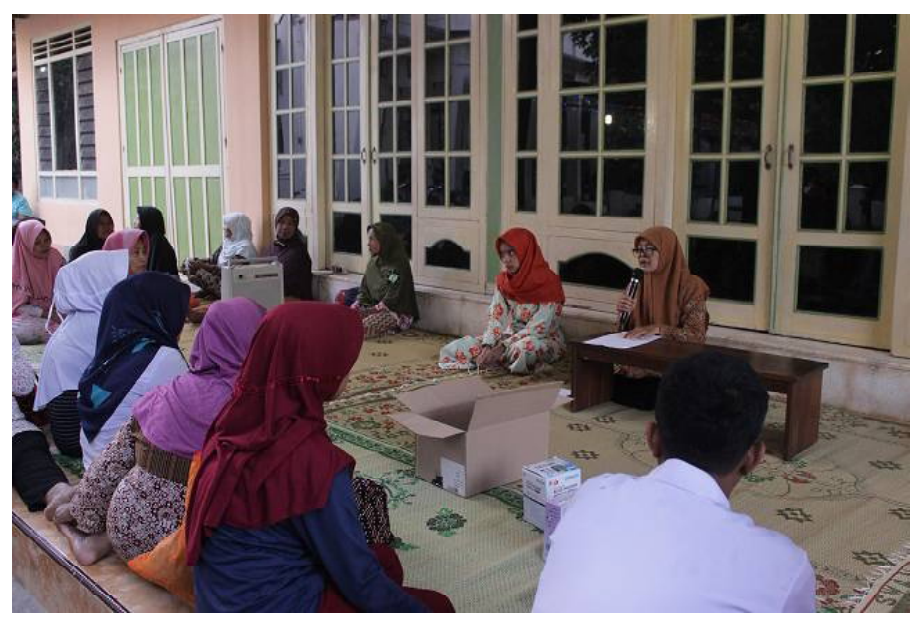

Gambar 4. Psikoedukasi Kesehatan Mental dan Spiritualitas Lansia

6. Supervisi Layanan Kesehatan Berkala dan Edukasi yang dilakukan Kegiatan ini dilakukan mulai pelaksanaan Layanan Kesehatan Berkala pertama dan dilanjutkan pada pelaksanaan lanjutan.

Berbagai kegiatan yangtelah dilakukan tersebut menjadikan luaran yang direncanakan dalam program ini dapat dicapai. Masyarakat telah mengalami transfer pengetahuai mengenai urgensi pemeriksaan kesehatan rutin. M erekajuga telah men genal sistem yang 
dapat digunakan dalam penyelenggarakan kegiatan tersebut. Selain itu, masyarakat juga telah memiliki sumber daya yang memadai untuk menjalankan kegiatan pemeriksaan kesehatan berkala secara swadaya. Telah terdapat kader kesehatan yang dapat menyelenggarakan pemeriksaan primer terhadap lansia. Perlengkapan untuk kegiatan tersebut juga telah tersedia.

Sinergi klinik sekitar yaitu Rahma M edika dengan masyarakat telah terpenuhi. Sinergi tercapai antara masyarakat Pedukuhan Dagen dengan Klinik R ahma M edika ditunjukkan dengan terciptanya sistem pemeriksaan mandiri oleh masyarakat terdidik sebagai deteksi dini dengan Klinik Rahma M edika sebagai rujukan untuk deteksi awal, pemeriksaan, dan penanganan lebih lanjut.

Berbagai hasil tersebut memungkinkan layanan kesehatan lansia secara swadaya dapat bertahan (sustainable) setelah program pengabdian selesai. Tercatat setelah pengabdian selesai dilakukan dua kali pemeriksaan kesehatan swadaya bekerjasama dengan klinik. Ketahanan tersebut bersumber dari kesadaran pribadi masyarakat yang dilengkapi den gan ketersediaan sumber daya. U ntuk mendukung keberlangsungan tersebut, pengabdi berkomitmen men gawasi pelaksanaan kegiatan pemeriksaan kesehatan masyarakat secara swadaya tersebut.

\section{SIMPULAN}

Terjadi perubahan kegiatan dikarenakan hal-hal baru yang ditemukan di lapangan. Walaupun demikian, target untuk mengadakan program pemeriksaan kesehatan swadaya telah berhasil. Keberhasilan tersebut terlihat dari terlaksananya pemeriksaan walaupun program pengabdian telah selesai. Bagi pelaksana program pengabdian disarankan untuk lebih sigap dalam melakukan perubahan sesuai kebutuhan di lapan gan, dan memperluas waktu asesmen program agar dapat memadai untuk pengabdi memahami kondisi lapangan.

\section{UCAPAN TERIMA KASIH}

Rasa terimakasih disampaikan kepada berbagai pihak yag telah mendukung terlaksananya program. Lembaga Penelitian, Publikasi dan Pengabdian M asyarakat (LP3M) Universitas M uhammadiyah Yogyakarta telah menyediakan pendanaan. Kepada masyarakat Dagen, Pendowoharjo, Sewon disampaikan terima kasih karena bersedia menjadi kancah pengabdian. Terima kasih juga disampaikan kepada Takmir Masjid M ifahul Jannah yang telah memberikan bantuan terlaksananya kegiatan ini. 


\section{DAFTAR PUSTAKA}

Arai $\mathrm{H}$, Ouchi $Y$, Yokode $\mathrm{M}$, Ito $\mathrm{H}$, Uematsu $\mathrm{H}$, Eto $\mathrm{F}$, Oshima S, Ota K, Saito Y, Sasaki H, Tsubota K, Fukuyama $\mathrm{H}$, Honda $\mathrm{Y}$, Iguchi A, Toba $\mathrm{K}$, Hosoi T, $\&$ Kita T. 2012. "Toward the realization of a better aged society: Messages from gerontology and geriatrics". Geriatrics \& Gerontology International, 12: 16-22.

Badan Pusat Statistik Bantul. 2017. Bantul dalam angka. Yogyakarta: Penyusun.

Badan Pusat Statistik Bantul. 2018. Bantul dalam angka. Yogyakarta: Penyusun.

Golinowska, S., Groot, W., Baji, P., \& Pavlova, M. 2016. Health promotion targeting older people. BMC Health Services Research 2016, 16 (Supplement 5): 345. doi: 10.1186/s12913016-1514-3

Hurlock, E. B. 2011. Psikologi Perkembangan: Suatu Pendekatan Sepanjang Rentang Kehidupan (terjemahan). J akarta: Erlangga.

Lazarus, R. S., \& Lazarus, B. N. 2006. Coping with aging. Oxford University Press: New York, NY.

Mier, N., Ory, M. G., Towne J r., S. D., \& Smith, M. L. 2017. "Relative association of multi-level supportive environments on poor health among older adults". International Journal of Environmental Research and Public Health, 14: 387. doi:10.3390/ijerph14040387
National Institute on Aging, National Institutes of Health, \& World Health Organization .2011. Global health and aging (NIH Publication no. 117737).

Pardiana, E. 2016. Baru 20\% Warga Sadar Kesehatan. Dilihat di www.mediaindonesia.con pada 7 Februari 2019.

Shrivastava, S. R. B. L., Shrivastava, P. S., \& Ramasamy, J. 2013. Health-care of Elderly: Determinants, Needs and Services. International Journal of Preventive Medicine, 4(10): 12241225.

Stuart-Hamilton, I. 2006. The Psychology Of Ageing: An Introduction, $4^{\text {th }}$ Ed. J essica Kingsley Publishers: London \& Philadelphia.

Yamaguchi M., Yoshida T., Yamada Y., Watanabe Y., Nanri H., Yokoyama K., Date H., Miyake M., Itoi A., Yamagata E., Masumoto T., Okayama Y., Yoshinaka Y., \& Kimura M. 2018.

"Sociodemographic and physical predictors of nonparticipation in community based physical checkup among older neighbors: a case-control study from the Kyoto-Kameoka longitudinal study, Japan". BMC Public Health, 18: 568. doi: 10.1186/s12889-018-5426-5. 